\title{
Persistent groin pain following a trans-obturator sling procedure for stress urinary incontinence: a diagnostic and therapeutic challenge
}

\author{
Menke H. Hazewinkel • Piet Hinoul • Jan-Paul Roovers
}

Received: 15 July 2008 / Accepted: 17 August 2008 / Published online: 4 September 2008

(C) The Author(s) 2008. This article is published with open access at Springerlink.com

\begin{abstract}
Groin pain after a tension-free vaginal tapeobturator (TVT-O) procedure can occur but mostly disappears within 4 weeks. Persistent groin pain is extremely rare and there is a paucity of literature on how to diagnose and manage this adverse event. We present two cases with severe persistent groin pain after uncomplicated TVT-O, in which magnetic resonance imaging and electromyography did not reveal the cause. We concluded that the tape entrapped or cut through peripheral branches of the obturator nerve. We removed as much of the tape as possible in both cases. Removal partially relieved the pain although sensory loss of the obturator nerve persisted 1 year after surgery. In case of abnormal post-operative groin pain, soon removal of the tape enhances the chance that damage to the obturator nerve is reversible, although it is important to counsel patients with similar pathology that recovery can take long and may be only partial.
\end{abstract}

Keywords Obturator nerve damage · Pain .

Tension-free vaginal tape-obturator . Therapy

\footnotetext{
M. H. Hazewinkel $(\bowtie) \cdot$ J.-P. Roovers

Department of Gynaecology, Academic Medical Center,

Meibergdreef 9,

1105 AZ Amsterdam, The Netherlands

e-mail: m.h.hazewinkel@amc.uva.nl

P. Hinoul

Department of Gynaecology, Oost-Limburg Hospital,

Genk, Belgium
}

\begin{abstract}
Abbreviations
EMG Electromyography

MRI Magnetic resonance imaging

SUI Stress urinary incontinence

TVT-O Tension-free vaginal tape-obturator

TENS Trans-cutaneous electrical nerve stimulation
\end{abstract}

\section{Introduction}

Mid-urethral trans-vaginal slings have become the surgical procedure of choice to treat stress urinary incontinence (SUI). The trans-obturator approach has a low risk of bladder and vascular injuries and post-operative voiding difficulties $[1,2]$. Transient post-operative groin pain occurs in $0.8-5 \%$ of patients which mostly resolves with analgesics within 1 month [3]. Persistent groin pain, however, is extremely rare and there is a paucity of literature on how to diagnose and manage this adverse event. We present two such cases.

\section{Cases}

Patient A, a 46-year-old multi-parous woman, presented with bothersome SUI confirmed by urodynamic investigations. After unsuccessful pelvic floor exercises, an uncomplicated tension-free vaginal tape-obturator (TVT-O; Ethicon, Somerville, NJ, USA) procedure was performed under general anaesthesia. Immediately post-operative, the patient experienced severe right groin pain for which intravenous pain medication was administered.

In the first post-operative day, the patient could not stand due to pain radiating from the right groin to the upper inner 
side of her knee, along the course of the obturator nerve. The neurologist found an intact motor function and concluded that oedema around the tape was compressing the obturator nerve. Surgery-related haemorrhage was excluded. Expectant management was advised. Physiotherapy was started and $50 \mathrm{mg}$ amitriptyline was prescribed. On the sixth post-operative day, the pain was under control to allow the patient to walk and she was discharged.

Invalidating pain persisted, however. Therefore, a magnetic resonance imaging (MRI) of the pelvis was performed 3 weeks after surgery. The right obturator nerve appeared to be intact. There was no suspicion of compression by a haematoma nor oedema. The polypropylene tape could not be visualised.

We expected the tape to compress or pass through a peripheral branch of the obturator nerve and removed the tape 4 weeks post-operatively. A mid-urethral incision was made and extended along the right lateral vaginal fornix. The tape was dissected to the level of the obturator membrane. It was attempted to remove as much as possible of the lateral part of the tape. It appeared that a small part of the tape which was localised far lateral could not be excised due to scarring around it. The left lateral part of the tape remained in place.

Continence was preserved after this but the right groin pain and the difficulty walking persevered. The consulted pain expert team diagnosed disturbed sensibility and allodynia of the medial part of the right thigh. They concluded that injury of a peripheral branch of the right obturator nerve was probable. Amitriptyline $75 \mathrm{mg}$ twice a day and pregabalin $75 \mathrm{mg}$ twice a day were prescribed. These adequately controlled the pain but caused bothersome concentration problems. Trans-cutaneous electrical nerve stimulation therapy was commenced and less pain medication could be administered. Presently, our patient has little pain but ongoing sensory problems.

Patient B, a 53-year-old multi-parous woman, presented with complaints of mixed urinary incontinence. The urge component was successfully treated with anti-cholinergic drugs. As pelvic floor exercises were unsuccessful for the SUI, a TVT-O was placed uncomplicatedly under general anaesthesia. The patient was discharged the next day.

Three days after surgery, the patient was re-admitted because of severe groin pain extending towards the right medial side of the knee. This pain had been present since surgery but had initially been interpreted by the patient as acceptable.

No signs of infection or haemorrhage were present. MRI of the pelvis showed oedema in both obturator spaces. Suspecting compression of the obturator nerve, diclofenac $100 \mathrm{mg}$ twice daily and intravenously administered morphine were prescribed. In the seventh post-operative day, the morphine could be stopped and the patient was discharged.

Because of persistent invalidating pain, we assumed the tape was entrapping or cutting through the obturator nerve.
Two weeks post-operatively, we removed the tape. Via a mid-urethral incision extended to the lateral fornix, the tape was followed past the obturator membrane and its lateral part was removed almost entirely. The mid-urethral and left lateral part of the tape were left in place. An attempt to remove the most distal part of the tape via the cutaneous route did not succeed because the tape could not be traced neither by ultrasound nor by surgical exploration.

Immediately after this procedure, the pain was considerably less, although paresthesia remained present. Electromyography (EMG) of the obturator nerve at this stage did not reveal motor nerve damage.

Six weeks after the partial removal of the tape, SUI symptoms recurred. One year after the first procedure, a retropubic TVT procedure was performed resulting in improvement of SUI. Although the groin pain had almost disappeared entirely, the sensory symptoms remained present.

\section{Discussion}

Persistent groin pain after an uncomplicated TVT-O procedure may be explained by damage of a peripheral branch of the obturator nerve. Such damage is rare but can occur even if the patient is correctly positioned and the surgeon is experienced, due to possible variability in the course of the TVT-O [4]. In two small cadaver studies, the track of the inside-out technique seems to approach the obturator nerve and vessels nearer as compared to the outside-in approach implying a higher risk of nerve and vascular injuries, although in a recent prospective comparison between the inside-out and outside-in technique, this difference was not confirmed by differences in clinical outcome parameters [5-7].

The presence of invalidating pain symptoms requires adequate diagnosis and therapy. Concerning diagnosis, physical examination and laboratory tests help to exclude haemorrhage and infection. MRI can visualise oedema, haemorrhage and the obturator nerve itself, but not the polypropylene tape nor smaller branches of the nerve. In the absence of motor dysfunction, a diagnostic role for EMG remains debatable.

Concerning therapy, the first step is to target neuropathic pain with oral analgesics. Due to systemic side effects, these are usually poorly tolerated. When nerve entrapment or damage is suspected, the next step could be injecting local analgesics, possibly in combination with corticosteroids [8]. In view of the use of synthetic grafts in the vagina, this option was waived as it might increase the chance of local infection. The ultimate option is to remove the tape, which should not be postponed too long as scarring around the tape progresses over time and makes total removal more difficult and nerve damage may become more irreversible after longer time. 


\section{Conclusion}

These two cases demonstrate that severe persistent groin pain following uncomplicated TVT-O procedures may have serious implications. In case severe groin pain does not dissipate within a few days, one may assume that direct damage in the course of the obturator nerve has occurred. We assumed that removal of the foreign body would allow the nerve lesion to heal. Both patients experienced pain relief after this. However, as the resolution of symptoms has been only partial, it is important to counsel patients with similar pathology that recovery takes time and may be incomplete. The sooner the tape is removed in case of abnormal post-operative groin pain, the better chance there is that the complete tape can be removed and that damage to the obturator nerve and its branches is reversible.

\section{Conflicts of interest None.}

Open Access This article is distributed under the terms of the Creative Commons Attribution Noncommercial License which permits any noncommercial use, distribution, and reproduction in any medium, provided the original author(s) and source are credited.

\section{References}

1. Charalambous S, Touloupidis S, Fatles G et al (2008) Transvaginal vs transobturator approach for synthetic sling placement in patients with stress urinary incontinence. Int Urogynecol J Pelvic Floor Dysfunct 19(3):357-360

2. Latthe PM, Foon R, Toozs-Hobson P (2007) Transobturator and retropubic tape procedures in stress urinary incontinence: a systematic review and meta-analysis of effectiveness and complications. BJOG 114(5):522-531

3. Meschia M, Bertozzi R, Pifarotti P et al (2007) Peri-operative morbidity and early results of a randomised trial comparing TVT and TVT-O. Int Urogynecol J Pelvic Floor Dysfunct 18(11):1257-1261

4. Hinoul P, Vanormelingen L, Roovers JP, de Jonge E, Smajda S (2007) Anatomical variability in the trajectory of the inside-out transobturator vaginal tape technique (TVT-O). Int Urogynecol J Pelvic Floor Dysfunct 18(10):1201-1206

5. Spinosa JP, Dubuis PY, Riederer BM (2007) Transobturator surgery for female stress incontinence: a comparative anatomical study of outside-in vs inside-out techniques. BJU Int 100(5):1097-1102

6. Zahn CM, Siddique S, Hernandez S, Lockrow EG (2007) Anatomic comparison of two transobturator tape procedures. Obstet Gynecol 109(3):701-706

7. Lee KS, Choo MS, Lee YS et al (2008) Prospective comparison of the 'inside-out' and 'outside-in' transobturator-tape procedures for the treatment of female stress urinary incontinence. Int Urogynecol J Pelvic Floor Dysfunct 19(4):577-582

8. Vervest HA, Bongers MY, van der Wurff AA (2006) Nerve injury: an exceptional cause of pain after TVT. Int Urogynecol J Pelvic Floor Dysfunct 17(6):665-667 